\title{
Delayed preconditioning with NMDA receptor antagonists in a rat model of perinatal asphyxia
}

\author{
Dorota Makarewicz ${ }^{1}$, Dorota Sulejczak ${ }^{2}$, Małgorzata Duszczyk ${ }^{1}$, Michał Małek ${ }^{1}$, Marta Słomka ${ }^{1}$, Jerzy W. Lazarewicz ${ }^{1}$ \\ ${ }^{1}$ Department of Neurochemistry, Mossakowski Medical Research Centre, Polish Academy of Sciences, Warsaw, ${ }^{2}$ Department \\ of Experimental Pharmacology, Mossakowski Medical Research Centre, Polish Academy of Sciences, Warsaw, Poland
}

\begin{abstract}
Introduction: In vitro experiments have demonstrated that preconditioning primary neuronal cultures by temporary application of NMDA receptor antagonists induces long-term tolerance against lethal insults. In the present study we tested whether similar effects also occur in brain submitted to ischemia in vivo and whether the potential benefit outweighs the danger of enhancing the constitutive apoptosis in the developing brain.

Material and methods: Memantine in pharmacologically relevant doses of $5 \mathrm{mg} / \mathrm{kg}$ or (+)MK-801 (3 mg/kg) was administered i.p. 24, 48, 72 and $96 \mathrm{~h}$ before 3-min global forebrain ischemia in adult Mongolian gerbils or prior to hypoxia/ ischemia in 7-day-old rats. Neuronal loss in the hippocampal CA1 in gerbils or weight deficit of the ischemic hemispheres in the rat pups was evaluated after 14 days. Also, the number of apoptotic neurons in the immature rat brain was evaluated. Results: In gerbils only the application of (+)MK-801 $24 \mathrm{~h}$ before ischemia resulted in significant prevention of the loss of pyramidal neurons. In rat pups administration of (+)MK-801 at all studied times before hypoxia-ischemia, or pretreatment with memantine or with hypoxia taken as a positive control 48 to $92 \mathrm{~h}$ before the insult, significantly reduced brain damage. Both NMDA receptor antagonists equally reduced the number of apoptotic neurons after hypoxia-ischemia, while (+)MK-801-evoked potentiation of constitutive apoptosis greatly exceeded the effect of memantine. Conclusions: We ascribe neuroprotection induced in the immature rats by the pretreatment with both NMDA receptor antagonists 48 to $92 \mathrm{~h}$ before hypoxia-ischemia to tolerance evoked by preconditioning, while the neuroprotective effect of (+)MK-801 applied $24 \mathrm{~h}$ before the insults may be attributed to direct consequences of the inhibition of NMDA receptors. This is the first report demonstrating the phenomenon of inducing tolerance against hypoxia-ischemia in vivo in developing rat brain by preconditioning with NMDA receptor antagonists.
\end{abstract}

Key words: apoptosis, gerbil, ischemia, neuroprotection, perinatal asphyxia, NMDA receptor.

\section{Introduction}

Brain ischemia, which encompasses a variety of forms including stroke, global brain ischemia evoked by cardiac arrest and perinatal asphyxia [45,69], is one of the most frequent causes of death and permanent disability in developed countries [56]. The cellular and molecular mechanisms of ischemia-evoked brain damage have been well documented. They include NMDA receptor mediated excitotoxicity, cal-

Communicating author:

Dorota Makarewicz, PhD, Laboratory of Pharmaconeurochemistry, Department of Neurochemistry, Mossakowski Medical Research Centre, Polish Academy of Sciences, Pawińskiego 5, 02-106 Warsaw, phone/fax: +48 226086623 , phone +48 226086578 , e-mail: dorota.makarewicz@gmail.com 
cium imbalance, oxidative stress and disturbed intracellular signaling $[5,14,25,50,51]$. These mechanisms appear to be promising targets for therapeutic interventions. For instance, preclinical studies demonstrated the neuroprotective potential of the NMDA receptor antagonists in in vitro and in vivo experimental models of brain ischemia [65], but these effects have been overshadowed by numerous side effects of (+)MK-801 and other high-affinity NMDA receptor antagonists in animals and humans $[26,44,66]$. Moreover, none of glutamate receptor antagonists or other potential neuroprotective drugs have positively passed the clinical tests in stroke [9]. In consequence, treatment of stroke is limited to thrombolytic therapy combined with improved care for stroke survivors [7,32], while hypothermia has been introduced in treating the victims of perinatal asphyxia and cardiac arrest $[20,58]$.

One of the novel therapeutic strategies in brain ischemia that are alternative to classical pharmacological neuroprotection is inducing brain tolerance to ischemia by its preconditioning with different stressors that are sublethal to neurons $[33,35,38]$ (for a recent review see [73]). These stressors may also be applied after the insult, and this promising therapeutic strategy is referred to as postconditioning $[7,19,74]$. Inducing brain tolerance to ischemia with pre- and postconditioning is still in the stage of preclinical tests or medical experiments. Several pathophysiological and mechanistic characteristics of this phenomenon have been revealed (for reviews see $[13,46]$ ). In particular the long list of preconditioning stressors includes hyperthermia, mild hypoxia and brief episodes of brain ischemia, as well as the application of different pharmacological compounds $[13,73]$. The role of activation of NMDA receptors in the mechanisms of inducing neuronal tolerance to hypoxia, ischemia and glutamatergic over-excitation has been repeatedly suggested $[22,31,59,72]$. These data seem to be consistent with the in vivo findings that (+)MK-801 inhibits ischemic preconditioning [6,33], although other data do not support these claims [15,71].

In addition to and independent of the possible role of NMDA receptor activation in the mechanisms of brain preconditioning, it has been demonstrated that even brief exposure of the primary cultures of hippocampal neurons to antagonists of NMDA receptors induces long lasting tolerance to excitotoxicity and to staurosporine-evoked apoptosis [64]. More recently we confirmed these data in cultured cere- bellar granule cells (CGC) [36]. In addition, our recent unpublished data demonstrate that in CGC both (+)MK-801 and memantine induce tolerance to oxygen and glucose deprivation (OGD), which is an in vitro model of brain ischemia. This suggests that inducing brain tolerance to ischemia may be a new mechanism of neuroprotection extended by NMDA receptor antagonists. However, it is not clear whether the results of experiments on neuronal cultures in vitro apply to all forms of brain ischemia in vivo, in both adult and immature subjects. Also, one should keep in mind the side effects of NMDA antagonists, which may outweigh the putative benefits. In particular this concerns the well-known apoptosis-inducing effect of high-affinity NMDA receptor antagonists in the developing brain $[28,47]$. Memantine is an NMDA receptor antagonist with low affinity, which has been approved in human medicine, particularly in the treatment of dementia in moderate-to-severe Alzheimer's disease [12,39]. A recent study examining the effects of NMDA receptor antagonists on constitutive apoptosis in the brain of normal immature rats demonstrated relatively low neurotoxicity of memantine compared to (+)MK-801 [42]. However, it is not known how apoptosis would be affected in the developing brain by superposition of memantine or (+)MK-801 application, and brain ischemia, which also induces apoptosis.

The aim of the present study was to evaluate the ability of NMDA receptor antagonists to induce tolerance to ischemia in vivo in animal models, taking into account their side effects in the developing brain. We used two uncompetitive antagonists with different affinities to NMDA receptors - (+)MK-801 and memantine. Global forebrain ischemia was induced in adult Mongolian gerbils by bilateral carotid occlusion, whereas hypoxia-ischemia in 7-day-old rats was a model of perinatal asphyxia. The latter animals were used to assess the effects of the NMDA receptor antagonists on constitutive and ischemia-induced apoptosis.

\section{Material and methods}

\section{Animals}

Male Mongolian gerbils (Meriones unguiculatus) and Wistar rats at postnatal day 7 (PND7) with their dams were bred in the Animal Colony of the Mossakowski Medical Research Centre, Polish Academy of Sciences in Warsaw. The animals were fed and water- 
ed ad libitum and kept on a $12: 12 \mathrm{~h}$ dark-light cycle, at room temperature with constant humidity of approximately $60 \%$. The experiments were conducted in conformity with the institutional guidelines, in compliance with the Polish governmental and the European Community regulations concerning experiments on animals. The Fourth Local Ethical Committee in Warsaw approved the procedures involving animals. All efforts were made to minimize animal suffering and the number of animals required.

\section{Induction of global forebrain ischemia and evaluation of neuronal damage in gerbils}

Mongolian gerbils aged 12-13 weeks, weighing about $60 \mathrm{~g}$, were randomly assigned to experimental groups. Global ischemia was induced according to Duszczyk et al. [15]. The gerbils were anesthetized with $4 \%$ halothane in a gas mixture containing $30 \% \mathrm{O}_{2}$ and $70 \% \mathrm{~N}_{2} \mathrm{O}$. Two minutes before the operation, halothane concentration was reduced to $2 \%$ and then maintained at this level during ischemia. The carotid arteries were isolated through an anterior midline cervical incision made after the injection of local anesthetics. Cerebral ischemia was induced by the occlusion of both common carotid arteries with miniature aneurismal clips for 3 min (test ischemia). Sham-operated animals were exposed to the

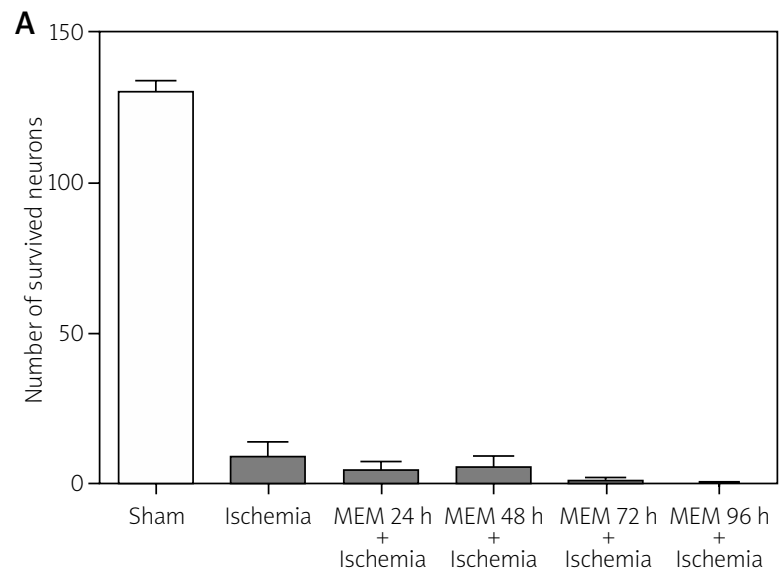

surgery without carotid occlusion. During the surgery animals were kept on a heating pad set at $38^{\circ} \mathrm{C}$. After wound closure, animals were kept at an ambient temperature of $21-24^{\circ} \mathrm{C}$ for 3-4 hours. Then the gerbils were moved to the animal house for 14 days. In this study, the mortality that could be associated with the experimental protocol was not observed.

Fourteen days after ischemia the animals were anesthetized with halothane and subjected to intracardiac perfusion fixation with $4 \%$ neutralized formalin solution. The brains were removed, immersed in $4 \%$ formalin solution for 1 week, transferred to absolute ethanol and embedded in paraffin. The $10 \mu \mathrm{m}$ thick cross sections from the dorsal part of the hippocampus at the level of between 2.2 and $3.5 \mathrm{~mm}$ posterior to Bregma were stained with cresyl violet. For each animal at least 5 sections of the central part of CA1 in both hippocampi were analyzed using a light microscope set at $\times 400$ magnification. The density of viable CA1 pyramidal neurons was quantified in ten $0.1 \mathrm{~mm}$ portions per section, and the average number of neurons is presented in Figure 1.

Moreover, in sham-operated gerbils, submitted to $3 \mathrm{~min}$ forebrain ischemia and preconditioned with (+)MK-801 or memantine 24, 48, 72, or 96 hours before test ischemia the nest building behavior was evaluated as has been described previously [16]. Some of these animals were subsequently used for

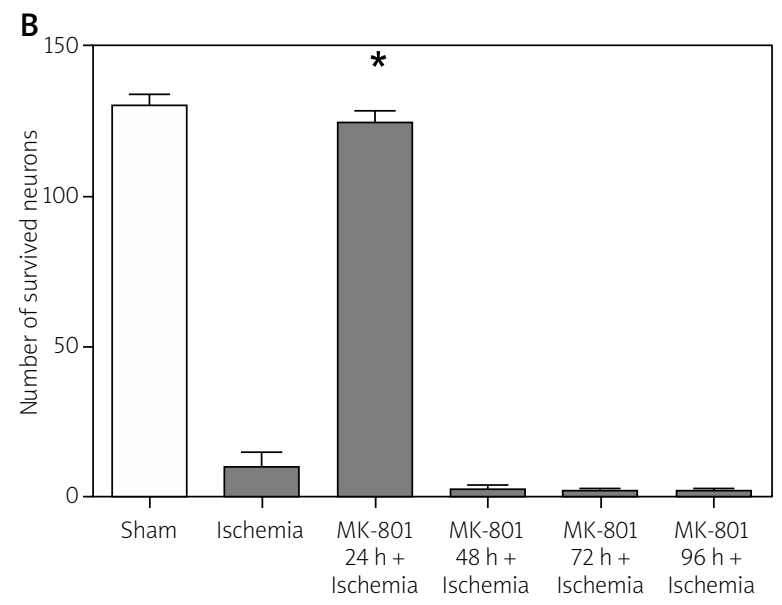

Fig. 1. The effect of preconditioning with NMDA receptor antagonists memantine (A) and (+)MK-801 (B) on CA1 lesion in a gerbil model of global cerebral ischemia. Memantine (MEM) in the dose of $5 \mathrm{mg} / \mathrm{kg}$ and (+)MK-801 in the dose of $3 \mathrm{mg} / \mathrm{kg}$ were applied i.p. 24, 48, 72 or 96 hours before brain ischemia evoked by 3-minute-long bilateral carotid occlusion. Histological damage in the CA1 area of the gerbil hippocampus was assessed 14 days after the insult. Bars represent means \pm SEM. Significant differences from the untreated ischemia were tested by ANOVA followed by Tukey's multiple comparison test. ${ }^{*} p<0.0001$ vs. 3 min ischemia. Group size: sham $n=10$; ischemia $n=9 ;(+)$ MK-801 each time group $n=10$. 
A

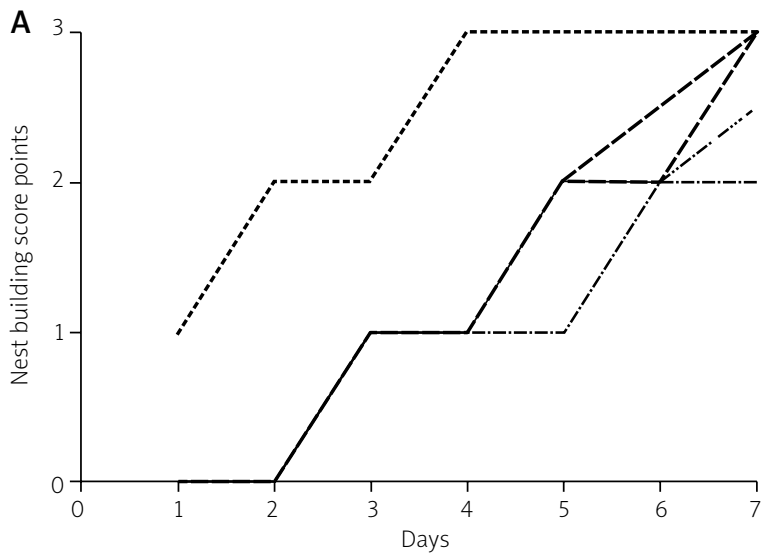

B

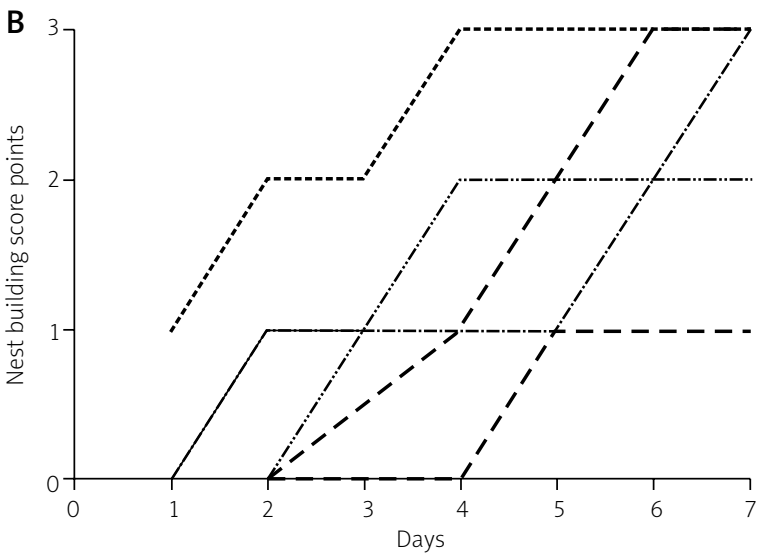

---- Sham --- Ischemia --- MEM $24 \mathrm{~h}+$ Ischemia - - MEM $48 \mathrm{~h}+$ Ischemia $\quad$-.-- MEM $72 \mathrm{~h}+$ Ischemia - - MEM $96 \mathrm{~h}+$ Ischemia -.-. Sham -.- Ischemia -.- MK-80124h+Ischemia - - MK-801 48 h+Ischemia -..- MK-80172h+Ischemia - - MK-80196h+Ischemia

Fig. 2. Nest-building behavior in gerbils after preconditioning with NMDA receptor antagonists: memantine (MEM) (A) in the dose of $5 \mathrm{mg} / \mathrm{kg}$ and (+)MK-801 (B) in the dose of $3 \mathrm{mg} / \mathrm{kg}$. Both substances were applied $24,48,72$ or 96 hours prior to ischemia. Nest building was assessed each day for 7 days following the ischemic episode. Values are median nest-building score, IQR for each data point $\leq 1$. Group size: sham $n=10$; ischemia $n=9 ;(+)$ MK-801 each time group $n=10$.

the evaluation of neuronal damage. One day after surgery, a paper towel was placed in each cage. Nest building was assessed each day for 7 days following the ischemic episode. Paper shredding was scored on a 4-point scale adapted from Baldwin et al. [1]: $0=$ none; $1=$ pieces $>4 \mathrm{~cm}^{2} ; 2=$ pieces between 2 and $4 \mathrm{~cm}^{2} ; 3=$ pieces $<2 \mathrm{~cm}^{2}$ (Fig. 2).

\section{Induction of hypoxia-ischemia in PND7 rats and evaluation of brain damage}

Hypoxia-ischemia (HI) in neonatal rats was induced according to Rice et al. [55] as had been described previously [41]. Wistar rat pups were anesthetized using halothane ( $4 \%$ for induction, and 1.5 $2.0 \%$ for maintenance) in a mixture of nitrous oxide and oxygen $(0.6: 1)$. The left common carotid artery was dissected. After surgery, the pups were left to recover for $1 \mathrm{~h}$. Then the litters were challenged for 75 min with a hypoxic gas mixture containing 7.3\% oxygen in nitrogen. The pups were then returned to their dams and housed at environmental temperature $\left(20^{\circ} \mathrm{C}\right)$, with a $12: 12 \mathrm{~h}$ light-dark cycle with ample food and water. Fourteen days after the insult (at PND21) the rats were anesthetized with halothane and decapitated. The cerebral hemispheres were weighed and brain damage was assessed by the deficit in weight of the ipsilateral (left) hemisphere and expressed as a percentage of the weight of the contralateral hemisphere [41] (Fig. 3).

\section{Hypoxic and pharmacological preconditioning}

In newborn rats, a hypoxic preconditioning procedure was used as a positive control to pharmacological preconditioning (see below). $24,48,72$ or 96 hours before hypoxia-ischemia the animals were submitted to hypoxia for 75 min with a hypoxic gas mixture containing $10.0 \%$ oxygen in nitrogen, at $35^{\circ} \mathrm{C} .(+) \mathrm{MK}-801$ maleate (dizocilpine; [5R,10S][+]-5-methyl-10,11-dihydro-5H-dibenzo[a,d]cyclohepten-5,10-imine) and memantine (3,5-dimethyladamantan-1-amine) were obtained from Tocris Bioscience (Bristol, UK). All other chemicals used for the dissolution of drugs were of analytical grade. For preconditioning of the animals, (+)MK-801 in a dose of $3 \mathrm{mg} / \mathrm{kg}$ or memantine in a dose of $5 \mathrm{mg} / \mathrm{kg}$ was dissolved in saline and applied as a single i.p. injection $24,48,72$ or 96 hours before hypoxia-ischemia. In selected experiments (Fig. 4) ebselen purchased from Santa Cruz Biotechnology Inc. (Dallas, TX, USA) and dissolved in 50\% DMSO + 50\% PEG30 was injected i.p. in the dose of $10 \mathrm{mg} / \mathrm{kg}, 30 \mathrm{~min}$ prior to the administration of NMDA receptor antagonists. In these experiments (+)MK-801 was applied 48 hours and memantine 72 hours before hypoxia-ischemia. In other groups only ebselen or its vehicle was injected $72 \mathrm{~h}$ before hypoxia-ischemia. The total volume of injected fluid was $50 \mu$ l. Moreover, in some experiments the rats at PND7 were injected 

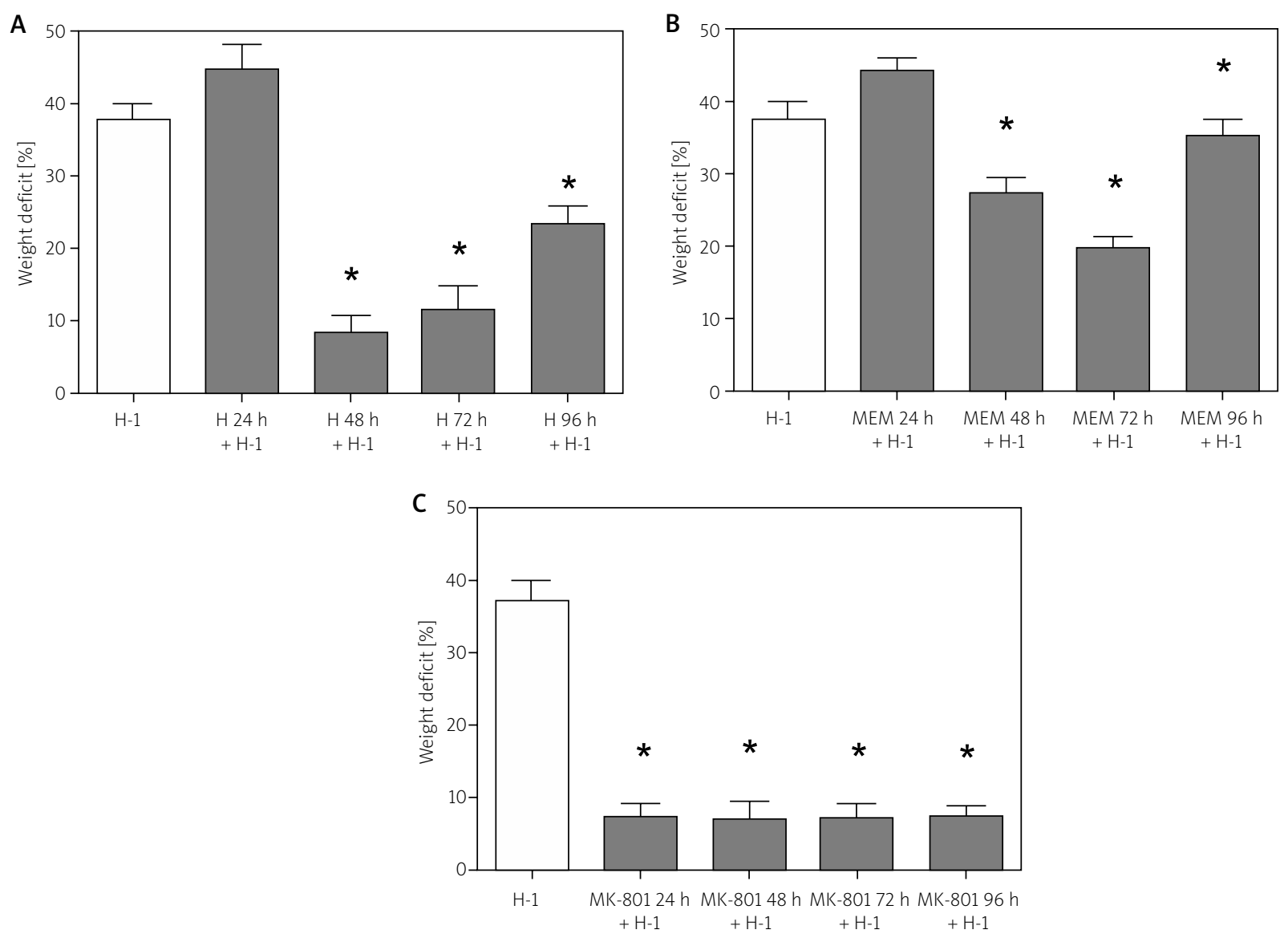

Fig. 3. The effects of preconditioning with hypoxia (A) or with NMDA receptor antagonists memantine (B) and $(+)$ MK-801 (C) on brain damage induced by hypoxia-ischemia in 7-day-old rats. Preconditioning with $7.2 \%$ $\mathrm{O}_{2}$ in $\mathrm{N}_{2}$ hypoxia $(\mathrm{H})$ for 75 minutes, and with (+)MK-801 or memantine (MEM) applied i.p. in the doses of $3 \mathrm{mg} / \mathrm{kg}$ or $5 \mathrm{mg} / \mathrm{kg}$, respectively, was performed $24,48,72$ or 96 hours before hypoxia-ischemia $(\mathrm{H}-\mathrm{I})$. Brain damage was evaluated by weighing the brain hemispheres 14 days after hypoxia-ischemia and expressed as the deficit in weight of the ipsilateral hemisphere in per cent of weight of the contralateral hemisphere. Bars represent means \pm SEM (group size: $n \geq 14$ rats per time point in each group). Significant differences from the ischemic control $(\mathrm{H}-\mathrm{I})$ were tested by ANOVA followed by Tukey's multiple comparison test. * $p<0.05$.

with NMDA receptor antagonists as described above, without following hypoxia-ischemia. After 14 days they were anesthetized with halothane and decapitated. The brains were removed, weighed and the results were compared to untreated control (Fig. 8).

\section{Histochemical analysis of immature rat brains}

In order to evaluate the effects of pharmacological preconditioning with memantine or (+)MK-801 72 or 48 hours before hypoxia-ischemia, respectively, on ischemia-induced apoptosis, the animals treated as described above were sacrificed 24 or 48 hours after hypoxia-ischemia. In turn, rats that were designed to study the effect of NMDA receptor antagonists on constitutive apoptosis, at PND7 received an intraperitoneal injection of memantine or (+)MK-801 as described above and were sacrificed 24 or 48 hours later. The animals were deeply anesthetized using Nembutal ( $80 \mathrm{mg} / \mathrm{kg}$ b.w., i.p.) and perfused through the ascending aorta with $0.9 \% \mathrm{NaCl}$ in $0.01 \mathrm{M}$ sodium-potassium phosphate buffer $\mathrm{pH} 7.4$ (PBS), followed by in situ perfusion-fixation with ice-cold fixatives applied under gravity. For the light microscopy $4 \%$ formaldehyde in $0.1 \mathrm{M}$ phosphate buffer $\mathrm{pH} 7.4$ was used as described previously [18]. Following perfusion, the brains were removed from 
the skulls and immersed for $2 \mathrm{~h}$ in the same fixing agent. Afterwards, the brains were saturated with sucrose through immersing in 10, 20 and 30\% (w/v) sucrose solutions in PBS and cut into $40 \mu \mathrm{m}$-thick free-floating coronal sections using a cryostat (CM 1850 UV, Leica, Germany). Morphology of cell nuclei was examined on brain sections mounted on microscope slides. Sections were washed in PBS and incubated in a $1 \mu \mathrm{g} / \mathrm{ml}$ solution of Hoechst stain (bisbenzimide dye, No 33258, B-2883, Sigma; prepared in PBS) for 2 minutes, at room temperature. The stain was then drained off and cover slipped with PBS for visualization. Induction of apoptosis was evaluated using a model Optiphot-2 Nikon fluorescent microscope (Japan) equipped with appropriate filters, and recorded with a DS-L1 Nikon camera (Japan). The number of apoptotic cells at the last stage of apoptosis (apoptotic bodies formation) was measured. Three to four animals from each experimental group were investigated. For each animal we analyzed 6-8 sections. The dying cells were counted within 10 microscopic fields of observation located randomly within the somatosensory region of the cerebral cortex (Figs. 5-7).

\section{Statistical methods}

All studies apart from nest building scores were performed with at least 9 or 10 rats or gerbils per time point in each group. Data were expressed as mean \pm SEM, and statistical analysis was performed by the ANOVA followed by post hoc Tukey's test. Nest building scores were presented as medians and tested by the Mann-Whitney $U$ test. Significance refers to results for which $p<0.05$ was obtained.

\section{Results}

\section{Tolerance to global forebrain ischemia in adult Mongolian gerbils induced by preconditioning with NMDA receptor antagonists}

In order to assess the ability of NMDA receptor antagonists to induce tolerance to brain ischemia in adult animals we used a gerbil model of global forebrain ischemia and evaluated the number of neurons in the hippocampal CA1 that survived 3-minute-long occlusion of the common carotid arteries. As presented in Figure $1 A-B$, 3-minute-long ischemia almost completely destroyed the pyramidal neurons. This effect remained unchanged after the injection of memantine 24, 48, 72

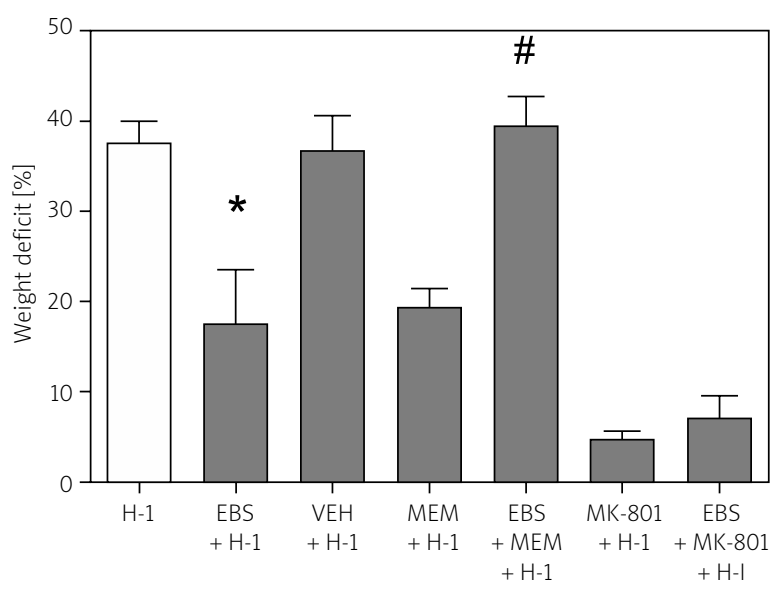

Fig. 4. Free radical scavenger ebselen reverses tolerance of 7-day-old rats to hypoxia-ischemia induced by preconditioning with memantine, but not that evoked by (+)MK-801. Rats were preconditioned with memantine (MEM) in the dose of $5 \mathrm{mg} / \mathrm{kg}$ or (+)MK-801 in the dose of $3 \mathrm{mg} / \mathrm{kg}$ applied i.p. $72 \mathrm{~h}$ or $48 \mathrm{~h}$ before hypoxiaischemia $(\mathrm{H}-\mathrm{I})$, respectively. Ebselen (EBS) in the dose of $10 \mathrm{~g} / \mathrm{kg}$ was applied i.p. 30 minutes before (+)MK-801 or memantine, otherwise EBS or vehicle (VEH) was applied alone $72 \mathrm{~h}$ before $\mathrm{H}$-I. Brain damage was evaluated by weighing the brain hemispheres 14 days after hypoxia-ischemia and expressed as the deficit in weight of the ipsilateral hemisphere in per cent of weight of the contralateral hemisphere. Bars represent means \pm SEM (group size: $n \geq 10$ rats per time point in each group). Significant differences from the appropriate ischemic control $(\mathrm{H}-\mathrm{I})$ were tested by ANOVA followed by Tukey's multiple comparison test. ${ }^{*} p<0.05$ vs. ischemic control $(\mathrm{H}-\mathrm{I}),{ }^{*} p<0.05$ vs. $M E M+\mathrm{H}-\mathrm{I}$.

and $96 \mathrm{~h}$ before the insult (Fig. 1A). (+)MK-801 injected $24 \mathrm{~h}$ before ischemia almost completely prevented neuronal damage in CA1; however, this neuroprotective effect disappeared with the extension of the interval between the pretreatment with (+)MK-801 and the induction of ischemia (Fig. 1B).

Figure 2 presents the nest building behavior score. These results demonstrate normal development of the nest building behavior in sham-operated animals, i.e. its immediate beginning and completion of the task after 4 days, while the animals submitted to 3-minute-long global forebrain ischemia showed a delay of two or three days in starting to build a nest, and this delay was maintained throughout the test 
A

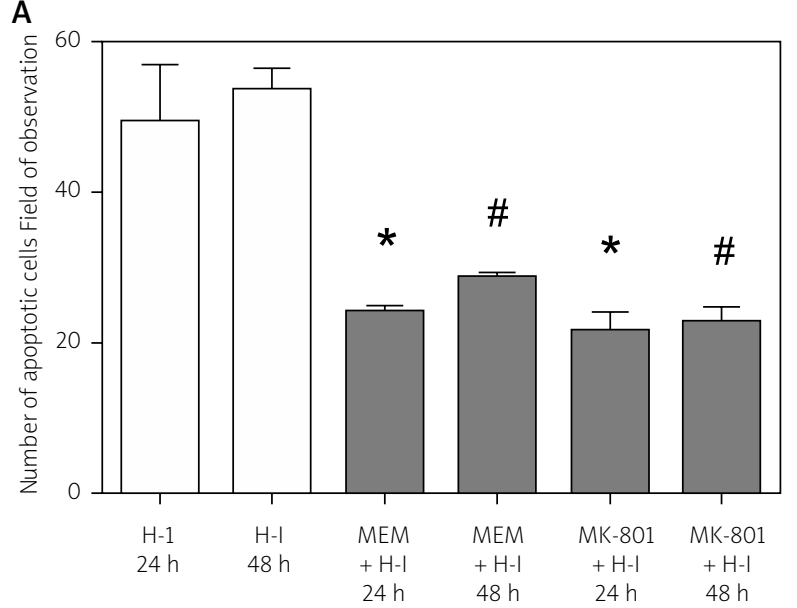

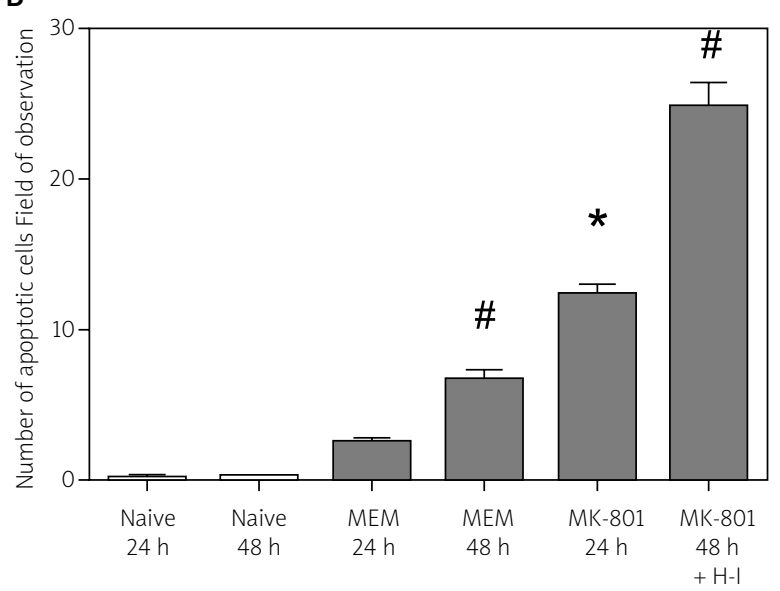

Fig. 5. The effect of NMDA receptor antagonists on hypoxia-ischemia evoked induction of brain apoptosis (A) and on constitutive apoptosis (B) in brain of immature rats. Memantine (MEM) in the dose of $5 \mathrm{mg} / \mathrm{kg}$ or (+)MK-801 in the dose of $3 \mathrm{mg} / \mathrm{kg}$ was applied i.p. to rats $72 \mathrm{~h}$ or $48 \mathrm{~h}$ before hypoxia-ischemia $(\mathrm{H}-\mathrm{I})$, respectively (A). Alternatively, the same doses of NMDA receptor antagonists were applied to untreated rats (B). The number of apoptotic cells was assessed 24 or 48 hours after $\mathrm{H}-\mathrm{I}$ (A) or after the application of NMDA receptor antagonists (B). Bars represent means \pm SEM $(n=3$ or 4 animals for each experimental group were investigated. For each animal we analyzed 6-8 sections). Significant differences from the appropriate ischemic control $(\mathrm{H}-\mathrm{I})$ were tested by ANOVA followed by Tukey's multiple comparison test. ${ }^{*} p<0.05$ vs. number of apoptotic cells assessed in the $24 \mathrm{~h}$ control group. $\# p<0.05$ vs. number of apoptotic cells assessed in the $48 \mathrm{~h}$ control group.
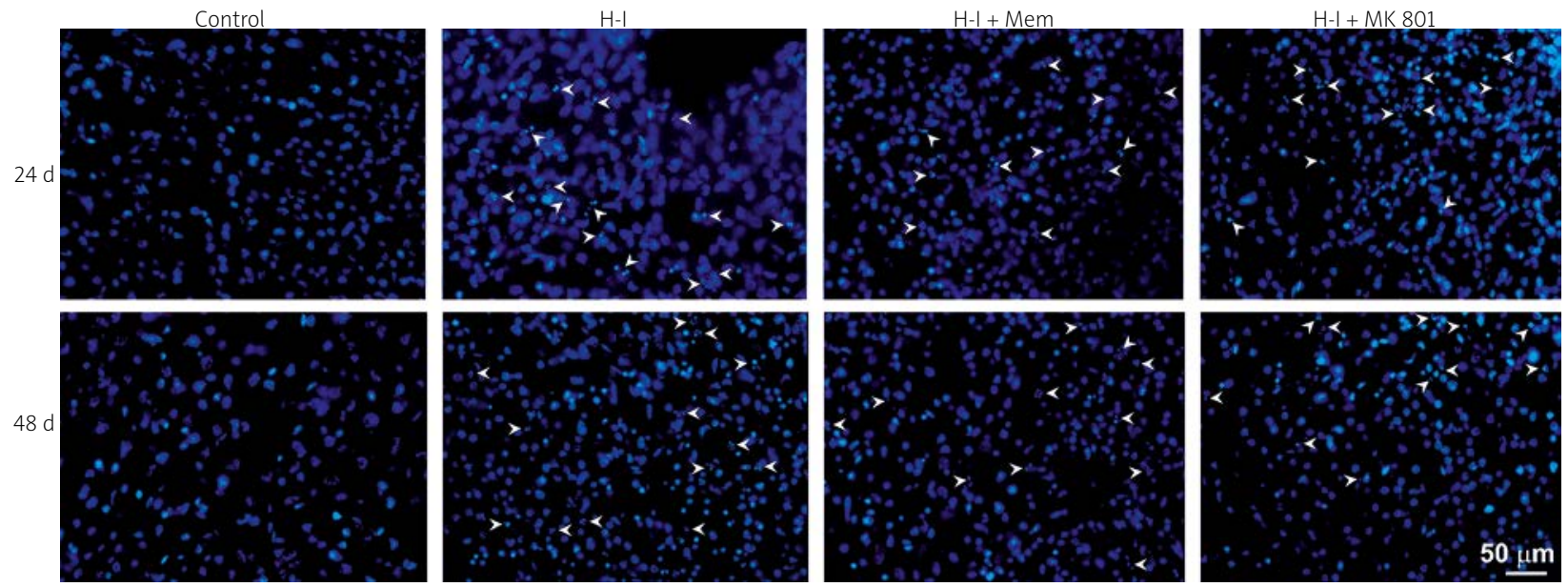

Fig. 6. Morphology of cortical cell nuclei visualized by Hoechst (bisbenzimide) staining. Note many apoptotic cells within the sections of rats subjected to HI. Note the reduction of apoptotic cell number within the material of animals pretreated with memantine or (+)MK 801. Arrowheads point to apoptotic bodies.

(Figs. 2A-B). Preconditioning with memantine had no effect on the nest building behavior after ischemia (Fig. 2A). Also, the application of (+)MK-801 did not improve the disturbances in the nest building behavior score evoked by cerebral ischemia, although a tendency for unspecific modifications of the behavior was observed in these groups (Fig. 2B).

\section{Tolerance to hypoxia-ischemia in 7-day-old rats induced by pre- conditioning with NMDA receptor antagonists}

In order to evaluate the effectiveness of brain tolerance against the ischemic insults that might be induced by the NMDA receptor antagonists in the 

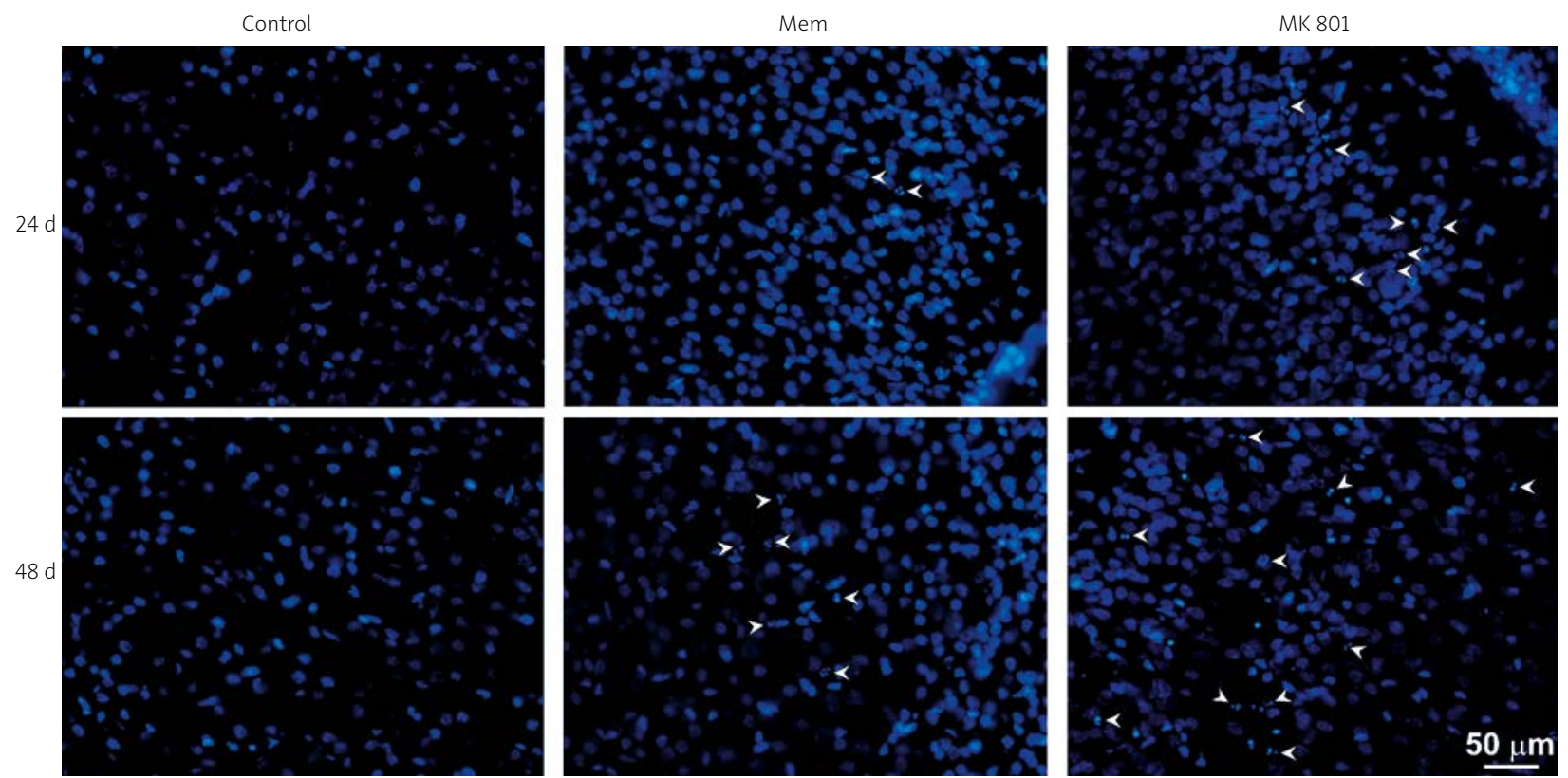

Fig. 7. Morphology of nuclei of cerebral cortex cells stained with Hoechst (bisbenzimide). Note the small number of apoptotic cells within the material from animals pretreated with memantine and higher number of apoptotic bodies in the sections of (+)MK 801 pretreated rats. Arrowheads point to apoptotic bodies.

immature animals we used hypoxia/ischemia in 7-day-old rats, which is an animal model of perinatal asphyxia. Like in the gerbil experiments, memantine or (+)MK-801 in single doses of $5 \mathrm{mg} / \mathrm{kg}$ and $3 \mathrm{mg} / \mathrm{kg}$ respectively, was injected into animals $24,48,72$ or 96 hours prior to the insult. As a positive control hypoxic preconditioning was used. For this purpose 75 -minute long episodes of normobaric hypoxia (10\% $\mathrm{O}_{2}$ in $\mathrm{N}_{2}$ ) were applied at the same times as pharmacological preconditioning. The obtained results demonstrated that untreated hypoxia/ischemia induces a deficit in the weight of ipsilateral (ischemic) brain hemisphere of almost $40 \%$ compared to the contralateral (control) hemisphere (Fig. 3).

As presented in Figure $3 \mathrm{~A}$, preconditioning with one episode of hypoxia applied $24 \mathrm{~h}$ before the insult tended to exacerbate brain damage evoked by hypoxia-ischemia. However, treatment with hypoxia $48 \mathrm{~h}$ before hypoxia-ischemia resulted in a highly significant reduction of the weight deficit by $73.6 \%$. Neuroprotection induced by hypoxic preconditioning and applied $72 \mathrm{~h}$ before hypoxia-ischemia remained at a similar level. Even $96 \mathrm{~h}$ after hypoxia, the neuroprotection was still significant as it remained at the level of $32.0 \%$ (Fig. 3A). As in the case of hypoxic preconditioning, pretreatment with memantine was also ineffective when applied $24 \mathrm{~h}$ before hypoxia-ischemia
(Fig. 3B). Application of memantine 48 and $72 \mathrm{~h}$ before the insult significantly reduced the brain weight deficit by $23.9 \%$, and $59.8 \%$, respectively. A 96-hour-long delay in testing with hypoxia-ischemia significantly reduced neuroprotection; however, the reduction of the brain weight deficit remained statistically significant (Fig. 3B). In turn, preconditioning with (+)MK-801 as early as $24 \mathrm{~h}$ before the insult resulted in a highly significant reduction of brain damage by about $80 \%$, and neuroprotection remained at the same level even when the antagonist was applied $96 \mathrm{~h}$ before hypoxia-ischemia (Fig. 3C).

To evaluate the role of oxidative stress in the induction by NMDA receptor antagonists of brain tolerance to hypoxia-ischemia, ebselen, a free radical scavenger, was injected 30 minutes before the application of memantine or (+)MK-801. After this treatment, hypoxia-ischemia was induced when the maximal neuroprotection by memantine or (+)MK-801 was observed, i.e. with a delay of $72 \mathrm{~h}$ or $48 \mathrm{~h}$, respectively (see Figs. 3B-C). As presented in Figure 4, ebselen completely reversed the neuroprotection induced by preconditioning with memantine, while the neuroprotection evoked by preconditioning with (+)MK-801 was practically unaffected. The unexpected result of this study was that injection of ebselen $72 \mathrm{~h}$ before hypoxia-ischemia itself 
induced significant neuroprotection as it reduced the level of brain damage to the range observed after preconditioning with memantine (Fig. 4).

\section{Effects of preconditioning with NMDA receptor antagonists on hypoxia/ ischemia-induced apoptosis in brain of immature rats}

In order to investigate the influence of NMDA receptor antagonists on apoptosis in the rat brain, evoked by hypoxia-ischemia, the animals were preconditioned 48 or 72 hours prior to hypoxia-ischemia with (+)MK-801 (3 mg/kg) or memantine (5 mg/kg), respectively. Then, the number of apoptotic neurons was assessed 24 or 48 hours after the insult. The results presented in Figure 5A and Figure 6 demonstrate that in a group of rats decapitated 24 or 48 hours after hypoxia-ischemia, the mean number of apoptotic cells per field of observation was 43.62 and 51.07, respectively. Preconditioning with memantine significantly reduced the number of apoptotic cells by $43.7 \%$ in the group studied $24 \mathrm{~h}$ after the insult and by $43.3 \%$ in the group studied $48 \mathrm{~h}$ after the insult. A similar effect was observed in the groups preconditioned with (+)MK-801, where the mean number of apoptotic cells was reduced by $53.14 \%$ and $54.1 \%$ in the groups studied 24 or 48 hours after hypoxia-ischemia, respectively.

\section{Effects of preconditioning with NMDA receptor antagonists on constitutive apoptosis and brain weight of immature rats}

As presented in Figure 5B and Figure 7, a low level of constitutive apoptosis in a developing rat brain was observed. The mean number of apoptosis per field of observation was 0.20 in PND7 rats and 0.24 in PND8 rats. These numbers represent the corresponding controls to groups treated with memantine or (+)MK-801 $48 \mathrm{~h}$ and $24 \mathrm{~h}$ earlier, respectively. A single injection of memantine increased the number of apoptotic cells up to 2.63 and 6.80 at 24 or 48 hours after the injection, respectively. Much more pronounced was the increase of the mean number of apoptotic cells per field of observation in brains of the rats that were preconditioned with (+)MK-801, which in the groups studied 24 or 48 hours after injection reached 12.18 and 25.32 , respectively.
For a rough assessment of the impact of a single injection of memantine or (+)MK-801 into immature rats on brain development, we compared the brain weight of the animals in the control-, (+)MK-801- and memantine-treated groups. As presented in Figure 8, injection of memantine $(5 \mathrm{mg} / \mathrm{kg})$ into 7 -day-old rats did not interfere with brain weight at postnatal day 21, whereas a single injection of (+)MK-801 $(3 \mathrm{mg} / \mathrm{kg}$ ) resulted in a statistically significant reduction in brain weight by $11.87 \%$.

\section{Discussion}

The results of this study demonstrate for the first time that a single administration of the NMDA receptor antagonist memantine or (+)MK-801 into immature rats induces in their brain in vivo a tolerance to hypoxia-ischemia lasting 48 to at least 96 hours. The free radical scavenger ebselen prevented memantine-induced neuroprotection. Moreover, pretreatment with memantine and (+)MK-801 reduced ischemia-evoked apoptosis in the immature rat brain. We attribute these effects to the phenomenon of brain preconditioning-induced tolerance against ischemia. In contrast to these findings, in the adult gerbil model of global forebrain ischemia, induction by memantine or (+)MK-801 of brain tolerance lasting longer than $24 \mathrm{~h}$ was not detected, which may suggest that only the early stages of the ontogenetic development of the brain may determine its susceptibility to preconditioning with the NMDA receptor antagonists. Our results also confirmed that application of (+)MK-801 significantly increases constitutive neuronal apoptosis in the developing brain, and demonstrated that such an effect of memantine, although noticeable, is less pronounced. We suggest the advisability of further studies on the possible use of memantine in the treatment of perinatal asphyxia.

In this work we utilized two distinct classical models of brain ischemia. Global forebrain ischemia in the adult Mongolian gerbils was induced by 3 -minute-long bilateral occlusion of the carotid arteries [34]. The rat model of perinatal asphyxia consists of submitting PND7 rats to unilateral carotid ligation combined with normobaric hypoxia, as was initially introduced by Rice et al. [55]. We have previous experience in using them in studies concerning induced tolerance to brain ischemia by preconditioning or postconditioning with various stressors such 


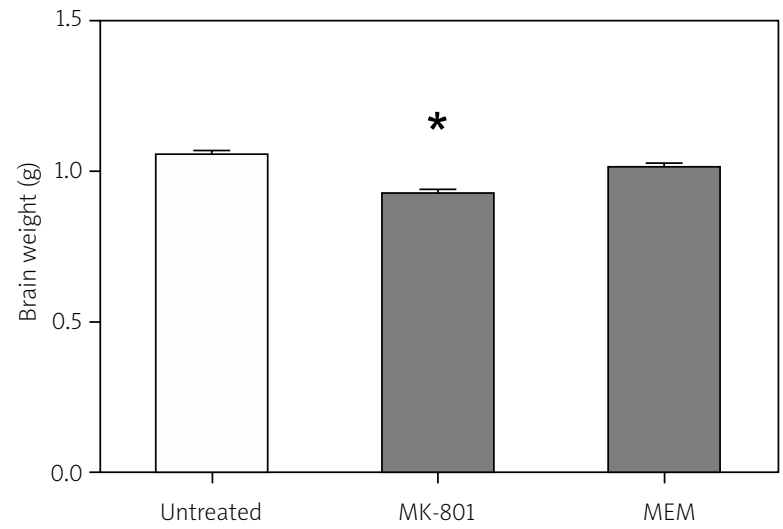

Fig. 8. The effect of NMDA receptor antagonists on brain weight. (+)MK-801 in the dose of $3 \mathrm{mg} / \mathrm{kg}$ and memantine (MEM) in the dose of $5 \mathrm{mg} / \mathrm{kg}$ were applied i.p. to rats at postnatal day 7. Two weeks later rats were decapitated, and brains were removed and weighed. Bars represent means \pm SEM (group size: $n \geq 5$ rats per time point in each group). Significant differences from the untreated rats were tested by ANOVA followed by Tukey's multiple comparison test. ${ }^{*} p<0.05$ vs. untreated.

as a sublethal short episode of ischemia or repeated hypobaric hypoxia $[16,17,19]$. In the gerbil model of global forebrain ischemia we used a simple and reliable method of counting the surviving neurons for the assessment of ischemia-induced loss of neurons in CA1 $[16,17]$. Also, the methods of evaluating brain damage induced by hypoxia-ischemia by measuring weight deficit of the ischemic hemispheres and counting the apoptotic neurons in the immature rat brain have been proven in our previous studies [16-18,30,41].

In these experiments, literature-based doses of (+)MK-801 and memantine were used. (+)MK-801 in a dose of $3 \mathrm{mg} / \mathrm{kg}$ has been previously shown to prevent neurodegeneration of CA1 pyramidal neurons in gerbils induced by bilateral carotid ligation [21]. Our previous studies demonstrated that (+)MK-801 at that dose failed to reduce the induction of brain tolerance by the ischemic preconditioning in gerbils [15]. It is known that (+)MK-801 in doses of $0.5-1 \mathrm{mg} / \mathrm{kg}$ is neuroprotective in the model of hypoxia-ischemia of PND7 rats $[22,61]$. Dosing of memantine in this study in relation to its therapeutic use in practical medicine requires additional comment. Memantine from $10 \mathrm{mg}$ twice daily up to $28 \mathrm{mg}$ once daily has been recommended for the treatment of moderate to severe Alzheimer's disease [3]. Since memantine metabolism in rodents is known to highly exceed that of humans [4,49], the relatively high dose of memantine $(5 \mathrm{mg} / \mathrm{kg})$ that was used in our study for gerbils and immature rats has been recommended as pharmacologically relevant and equivalent of the therapeutic dose of memantine in Alzheimer's disease therapy [24]. It should be noted that the doses of (+)MK-801 and memantine applied in this study are not comparable in terms of levels of the NMDA receptor blockade. Based on the affinity for the NMDA receptor and behavioral outcomes, and on the estimated concentrations of these substances in brain, a dose of (+)MK-801 corresponding to a $5 \mathrm{mg} / \mathrm{kg}$ dose of memantine would be $0.01-0.02 \mathrm{mg} / \mathrm{kg}$ [70]. Therefore some differences observed in this study which will be discussed below could result from using not equivalent doses, not only from qualitative differences between these two agents. However, these differences are intentional. We used in this work a high dose of (+)MK-801 to determine the maximum level of neuroprotection induced by preconditioning with the NMDA receptor antagonists.

For the purposes of discussion, the results of this study concerning the induction of tolerance to ischemia by administration of NMDA receptor antagonists have been divided into two groups. One of them demonstrated that both (+)MK-801 and memantine applied 48, 76 and $92 \mathrm{~h}$ before test ischemia induce neuroprotection in the immature rats, but not in adult gerbils. The other set of data indicates that pretreatment of the adult gerbil and the rat pups with (+)MK-801, but not with memantine, $24 \mathrm{~h}$ before the ischemic insults, results in significant neuroprotection. We interpret differently these two groups of results. Then, we will discuss separately the results concerning the interference of NMDA receptor antagonists with ischemia-induced and constitutive apoptosis in the immature rat brain.

Preconditioning of the rat pups with a single episode of normobaric hypoxia was used in our study as a positive control for induced tolerance to hypoxia-ischemia. Other researchers who have also used preconditioning of immature rats with hypoxia observed protection against hypoxia-ischemia as early as after $24 \mathrm{~h}$ and within the next few days $[60,67]$. Interestingly, our data demonstrated neuroprotection, provided that preconditioning with hypoxia was applied 48,72 or $96 \mathrm{~h}$, but not $24 \mathrm{~h}$, before the insult (Fig. 3A). Further studies are needed 
to determine the cause of these discrepancies with the previously published literature. Nevertheless, we consider the observed pattern of development of tolerance induced by preconditioning carried out in infant rats with hypoxia as the characteristic feature of our experimental model of preconditioning. Our present data consistently showed that also memantine applied 48, 72 and 96 hours, but not 24 hours, before the insult induced neuroprotection (Fig. 3B). Also, pretreatment with (+)MK-801 2, 3 and 4 days before the insult resulted in robust protection of the immature rat brain (Fig. 3C). Consequently, we ascribe these neuroprotective effects of pretreatment of the rat pups with the NMDA receptor antagonists to the common mechanism of preconditioning and induction of tolerance to hypoxia-ischemia. Indeed, this phenomenon meets the criteria of delayed preconditioning, in which a lag between the preconditioning stimulus and development of tolerance is necessary to induce synthesis of proteins involved in neuroprotection $[2,8,13,52]$. Tremblay et al. [64] in their pioneering in vitro study demonstrated that administration of the protein synthesis inhibitor during the first few hours after preconditioning with (+)MK-801 prevented induction of tolerance in the primary cultures of the rat cortical neurons. The other characteristic feature of preconditioning inducing delayed tolerance against brain ischemia is the involvement of oxidative stress in triggering the neuroprotective mechanisms [52]. Consistently with that, in our experiments the free radical scavenger ebselen administered to the rat pups 30 minutes before preconditioning with memantine reversed brain tolerance to hypoxia-ischemia (Fig. 4). Resistance of the preconditioning with (+)MK-801 to the inhibition by ebselen may result from very high stress which the brain is submitted to by tonic (+)MK-801-evoked inhibition of the NMDA receptors, which could not be reversed by a single injection of ebselen.

In agreement with our previous data [15] using the gerbil model of global forebrain ischemia, in the present study robust damage to the hippocampal CA1 pyramids 14 days after 3-minute-long ischemia was observed. In contrast to the aforementioned data from the rat model of perinatal asphyxia, our results demonstrated that application of (+)MK-801 or memantine to gerbils 48, 72 and $96 \mathrm{~h}$ before ischemia does not induce morphological or behavioral neuroprotection (Figs. 1 and 2). Based on these results, we assume that under the conditions of this study NMDA receptor antagonists do not induce long-lasting ischemic tolerance of the hippocampal neurons in adult gerbils. It is tempting to generalize these results and to argue that resistance to preconditioning with the NMDA receptor antagonists is the characteristic feature of adult animals or of the model of global brain ischemia. However, further studies are needed to test these and other alternative explanations, including the one suggesting that a very high level of neuronal loss after 3-minute-long ischemia, which was observed in our present experiments, precluded any neuroprotective effect of tolerance.

Another interesting result obtained from the experiments in which we tested the potential of (+)MK-801 to induce tolerance of the gerbils and immature rats against the ischemic insult is the occurrence of neuroprotection when (+)MK-801, but not memantine, was applied $24 \mathrm{~h}$ before the insult (Figs. 1 and 3). We do not attribute that phenomenon to the tolerance to ischemia induced by preconditioning because such early and transitory neuroprotection does not correspond to the characteristics of delayed preconditioning after which tolerance to ischemia persists for several days [13]. Instead, we interpret this effect observed in gerbils and the neuroprotection obtained with (+)MK-801 (but not with memantine) administered to PND7 rats $24 \mathrm{~h}$ before hypoxia-ischemia (Fig. 3C) as the effect of persistent presence of (+)MK-801 in the brain and its direct inhibition of the NMDA receptors during ischemia. (+)MK-801 is known to block the channel of NMDARs for a long time even after its washing out from the extracellular space [54]. Although the time required for $50 \%$ elimination $\left(T_{1 / 2}\right)$ of $(+)$ MK-801 in the brain of rats has been evaluated to be at the level of 2 hours [68], behavioral studies of Lysko et al. [40] demonstrated prolonged effects of a single injection into Mongolian gerbils of $3 \mathrm{mg} / \mathrm{kg}(+) \mathrm{MK}-801$, pointing to the physical presence of this inhibitor in brain. In their studies, the hypothermic response was maintained at a maximal level for at least 24 hours. Moreover, the recovery of motor functions from severe ataxia was slow, and the time required for 50\% recovery $\left(T_{1 / 2}\right)$ of 11 hours was found [40]. Although we do not have information from the literature on the (+)MK-801 elimination half-life in the developing rat brain, Schwartz and Westerlain [57] demonstrated that the kinetics of (+)MK-801 accumulation in 
the PND7 rat brain does not differ significantly from that of an adult rat [68], which may suggest that its elimination from the brain is also similar. Both direct inhibition of NMDA receptors, which are involved in brain injury caused by ischemia [62], and prolonged hypothermia in (+)MK-801-treated animals [11] may be responsible for neuroprotection. In addition, our present results obtained in the gerbil model of global brain ischemia demonstrate that (+)MK-801, which persists for a long time in the brain and induces by itself a delayed tolerance to ischemia, is not a good tool to study the participation of NMDA receptors in the mechanisms of brain ischemic preconditioning (compare $[6,15,33,71]$ ).

Our promising results, showing for the first time that in vivo in the developing rat brain preconditioning with (+)MK-801 induces tolerance to hypoxia-ischemia, have been overshadowed by the induction by this high-affinity NMDA receptor antagonist of constitutive apoptosis (Fig. 5A). This phenomenon has been previously demonstrated $[27,47]$. On the other hand, data from both in vitro and in vivo studies indicate that memantine by itself does not induce massive constitutive apoptosis in a developmentally relevant model of primary neuronal cultures [29] or in the brain of control, otherwise untreated rat pups [42]. Our present results showed that although the effectiveness of memantine applied at a therapeutic dose of $5 \mathrm{mg} / \mathrm{kg}$ in inducing constitutive apoptosis is approximately 3.5 to 5 times lower than that of (+)MK-801 (3 mg/kg), it is still considerable (Fig. 5A). The key issue was how the preconditioning with (+)MK-801 and memantine affects apoptosis induced by hypoxia-ischemia in the developing rat brain. Our present results (Fig. 5B) demonstrate that preconditioning of the immature rats with (+)MK-801 and memantine significantly and with approximately the same potency reduces ischemia-induced apoptosis in the brains of these animals. The previous studies demonstrated neuroprotection, inhibition of caspases and decrease in the number of apoptotic neurons with DNA fragmentation in the brain of immature rats treated with (+)MK-801 or memantine during or immediately after hypoxia-ischemia $[37,53]$. However, ours is the first report demonstrating the antiapoptotic potential of preconditioning of the immature rats with (+)MK-801 or memantine. These results are consistent with the in vitro findings of Tremblay et al. [64] that preconditioning of the pri- mary cortical neurons with (+)MK-801 prevents staurosporine-induced apoptosis.

Due to the very well-known side effects of (+)MK-801 treatment, particularly its toxicity in the developing brain, our data presenting neuroprotective effects of preconditioning with (+)MK-801 via the induction of tolerance against ischemia are of purely cognitive significance. However, the results of our study concerning the effects of memantine may have potential practical value. Memantine administered in a therapeutic dose appeared to be equally effective as (+)MK-801 in preventing apoptosis induced by hypoxia-ischemia in the developing rat brain, being a several times weaker inducer of constitutive apoptosis. In contrast to Manning et al. [42], who assumed that memantine exhibits relative safety, we observed some hazardous effects of its use in neonatal rats. Memantine is widely used in adults for the treatment of dementia, particularly of the Alzheimer's type [49], and its safety has been demonstrated [63]. There have also been clinical tests evaluating the therapeutic potential of memantine in children diagnosed with developmental disorders including autism $[10,48]$. It appeared protective in the treatment of periventricular leukomalacia in a rat model [43] and neuroprotective in hypoxia-ischemia in PND7 rats [37]. Our present study presented a novel strategy in the therapeutic use of memantine to induce tolerance to ischemia in the developing brain. Although preconditioning may be of limited utility, there are indications that induction of tolerance to brain ischemia by postconditioning may also be an effective way of neuroprotection, as this phenomenon probably uses mechanisms of induction and expression similar to preconditioning (for a review see [13]).

In conclusion, this study demonstrates for the first time that a single injection of memantine in a therapeutic dose of $5 \mathrm{mg} / \mathrm{kg}$ or of (+)MK-801 in a high dose of $3 \mathrm{mg} / \mathrm{kg}$ induces tolerance to hypoxia-ischemia in neonatal rats, which persists for 48-96 hours and is similar to the neuroprotective effects of preconditioning with normobaric mild hypoxia. We ascribe this effect to the phenomenon of delayed preconditioning and we differentiate it from the direct neuroprotective action of (+)MK-801 which may persist for up to 24 hours after injection. However, we did not find delayed tolerance against global forebrain ischemia after injecting these NMDA receptor antagonist into Mongolian gerbils. The neuroprotective effect of pre- 
treatment of the rat pups with memantine may be reversed by application of the free radical scavenger ebselen, which is in accordance with the role of preconditioning in that process. Thus, our data demonstrate that neuroprotection of the developing brain with NMDA receptor antagonists may be achieved under two different routes: by direct inhibition of these receptors during and just after the insult, or by pharmacological preconditioning and gaining induced delayed tolerance to ischemia. Moreover, we evaluated the toxicity of (+)MK-801 and memantine in the developing rat brain. Our data confirmed previous information on the significant potentiation by (+)MK-801 of constitutive apoptosis, while such an effect of memantine was considerably less pronounced. However, both (+)MK-801 and memantine equally inhibited apoptosis induced by ischemia. This indicates that memantine may be considered as a promising candidate for further studies on brain protection in perinatal asphyxia.

\section{Acknowledgements}

This study was supported by grant no. N N401 066738 from the Polish Ministry of Science and Higher Education. The expert technical assistance of Mrs Apolonia Ziembowicz is gratefully acknowledged.

\section{Disclosure}

Authors report no conflict of interest.

\section{References}

1. Baldwin HA, Jones JA, Cross AJ, Green AR. Histological, biochemical and behavioural evidence for the neuroprotective action of chlormetiazole following prolonged carotid occlusion. Neurodegeneration 1993; 2: 139-146.

2. Barone FC, White RF, Spera PA, Ellison J, Currie RW, Wang X, Feuerstein GZ. Ischemic preconditioning and brain tolerance: temporal histological and functional outcomes, protein synthesis requirement, and interleukin-1 receptor antagonist and early gene expression. Stroke 1998; 29: 1937-1950.

3. Bassil N, Thaipisuttikul P, Grossberg GT. Memantine ER, a oncedaily formulation for the treatment of Alzheimer's disease. Expert Opin Pharmacother 2010; 11: 1765-1771.

4. Beconi MG, Howland D, Park L, Lyons K, Giuliano J, Dominguez C, Munoz-Sanjuan I, Pacifici R. Pharmacokinetics of memantine in rats and mice. PLOS Curr 2012 Feb 15. Edition 1. doi: 10.1371/ currents.RRN1291.

5. Belousov AB. Novel model for the mechanisms of glutamatedependent excitotoxicity: role of neuronal gap junctions. Brain Res 2012; 1487: 123-130.
6. Bond A, Lodge D, Hicks CA, Ward MA, O'Neill MJO. NMDA receptors antagonism, but not AMPA receptors antagonism attenuates induced ischemic tolerance in gerbil hippocampus. Eur J Pharmacol 1999; 380: 91-99.

7. Brainin M, Zorowitz RD. Advances in stroke: recovery and rehabilitation. Stroke 2013; 44: 311-313.

8. Burda J, Hrehorovská M, Bonilla LG, Danielisová V, Cízková D, Burda R, Némethová M, Fando JL, Salinas M. Role of protein synthesis in the ischemic tolerance acquisition induced by transient forebrain ischemia in the rat. Neurochem Res 2003; 28: 1213-1219.

9. Cheng YD, Al-Khoury L, Zivin JA. Neuroprotection for ischemic stroke: two decades of success and failure. NeuroRx 2004; 1: 36-45.

10. Chez MG, Burton Q, Dowling T, Chang M, Khanna P, Kramer C. Memantine as adjunctive therapy in children diagnosed with autistic spectrum disorders: an observation of initial clinical response and maintenance tolerability. J Child Neurol 2007; 22: 574-579.

11. Corbett D, Nurse S, Colbourne F. Hypothermic neuroprotection. A global ischemia study using 18- to 20-minth-old gerbils. Stroke 1997; 28: 2238-2243.

12. Danysz W, Parsons CG. Alzheimer's disease, $\beta$-amyloid, glutamate, NMDA receptors and memantine - searching for the connections. Br J Pharmacol 2012; 167: 324-352.

13. Dirnagl U, Becker K, Meisel A. Preconditioning and tolerance against cerebral ischaemia: from experimental strategies to clinical use. Lancet Neurol 2009; 8: 398-412.

14. Doyle KP, Simon RP, Stenzel-Poore MP. Mechanisms of ischemic brain damage. Neuropharmacology 2008; 55: 310-318.

15. Duszczyk M, Gadamski R, Ziembowicz A, Danysz W, Lazarewicz JW. NMDA receptor antagonism does not inhibit induction of ischemic tolerance in gerbil brain in vivo. Neurotox Res 2005; 7: 283-292.

16. Duszczyk M, Ziembowicz A, Gadamski R, Lazarewicz JW. Behavioral evaluation of ischemic damage to CA1 hippocampal neurons: effects of preconditioning. Acta Neurobiol Exp (Wars) 2006; 66: 311-319.

17. Duszczyk M, Ziembowicz A, Gadamski R, Wieronska JM, Smialowska M, Lazarewicz JW. Changes in the NPY immunoreactivity in gerbil hippocampus after hypoxic and ischemic preconditioning. Neuropeptides 2009; 43: 31-39.

18. Frontczak-Baniewicz M, Chrapusta SJ, Sulejczak D. Long-term consequences of surgical brain injury - characteristics of the neurovascular unit and formation and demise of the glial scar in a rat model. Folia Neuropathol 2011; 49: 204-218.

19. Gamdzyk M, Makarewicz D, Słomka M, Ziembowicz A, Salinska E. Hypobaric hypoxia postconditioning reduces brain damage and improves antioxidative defense in the model of birth asphyxia in 7-day-old rats. Neurochem Res 2014; 39: 68-75.

20. Gancia P, Pomero G. Therapeutic hypothermia in the prevention of hypoxic-ischaemic encephalopathy: new categories to be enrolled. J Matern Fetal Neonatal Med 2012; 25 Suppl 4: 94-96.

21. Gill R, Foster AC, Woodruff GN. MK-801 is neuroprotective in gerbils when administered during the post-ischaemic period. Neuroscience 1988; 25: 847-855. 
22. Gilland E, Hagberg H. Is MK-801 neuroprotection mediated by systemic hypothermia in the immature rat? Neuroreport 1997 8: 1603-1605.

23. Grabb MC, Choi DW. Ischemic tolerance in murine cortical cell culture: critical role for NMDA receptors. J Neurosci 1999; 19 1657-1662.

24. Guadagna S, Bundgaard C, Hovels $\varnothing$ N, Volbracht C, Francis PT, Egebjerg J, Sotty F. Memantine potentiates hippocampal $\theta$ os cillations at a therapeutic dose in anesthetized mice: a mechanistic link to its cognitive-enhancing properties. Neuropharmacology 2012; 62: 2208-2218.

25. Guo MF, Yu JZ, Ma CG. Mechanisms related to neuron injury and death in cerebral hypoxic ischaemia. Folia Neuropathol 2011 49: 78-87.

26. Hargreaves RJ, Hill RG, Iversen LL. Neuroprotective NMDA antagonists: the controversy over their potential for adverse effects on cortical neuronal morphology. Acta Neurochir Suppl (Wien) 1994; 60: 15-19.

27. Ikonomidou C, Bosch F, Miksa M, Bittigau P, Vöckler J, Dikranian K, Tenkova TI, Stefovska V, Turski L, Olney JW. Blockade of NMDA receptors and apoptotic neurodegeneration in the developing brain. Science 1999; 283: 70-74.

28. Ikonomidou C. Triggers of apoptosis in the immature brain. Brain Dev 2009; 31: 488-492.

29. Jantas D, Lasoń W. Anti-apoptotic effect of memantine against staurosporine- and low-potassium-induced cell death in cerebellar granule cells: a development-dependent effect. Pharmacol Rep 2009; 61: 827-937.

30. Kajta M, Makarewicz D, Ziemińska E, Jantas D, Domin H, Lasoń W Kutner A, Łazarewicz JW. Neuroprotection by co-treatment and post-treating with calcitriol following the ischemic and excitotoxic insult in vivo and in vitro. Neurochem Int 2009; 55: 265-274.

31. Kasischke K, Ludolph AC, Riepe MW. NMDA-antagonists reverse increased hypoxic tolerance by preceding chemical hypoxia. Neurosci Lett 1996; 214: 175-178.

32. Kaste M. Stroke: advances in thrombolysis. Lancet Neurol 2013; 12: $2-4$

33. Kato H, Liu Y, Araki T, Kogure K. MK-801, but not anisomycin, inhibits the induction of tolerance to ischemia in the gerbi hippocampus. Neurosci Lett 1992; 139: 118-121.

34. Kirino T, Sano K. Selective vulnerability in the gerbil hippocampus following transient ischemia. Acta Neuropathol 1984; 62 201-208.

35. Kitagawa K, Matsumoto M, Tagaya M, Hata R, Ueda H, Niinobe M Handa N, Fukunaga R, Kimura K, Mikoshiba K, et al. 'Ischemic tolerance' phenomenon found in the brain. Brain Res 1990; 528: 21-24.

36. Kuszczyk M, Słomka M, Antkiewicz-Michaluk L, Salińska E, Łazarewicz JW. 1-Methyl-1,2,3,4-tetrahydroisoquinoline and established uncompetitive NMDA receptor antagonists induce tolerance to excitotoxicity. Pharmacol Rep 2010; 62: 1041-1050.

37. Liu C, Lin N, Wu B, Qiu Y. Neuroprotective effect of memantine combined with topiramate in hypoxic-ischemic brain injury. Brain Res 2009; 1282: 173-182.

38. Liu Y, Kato H, Nakata N, Kogure K. Protection of rat hippocampus against ischemic neuronal damage by pretreatment with sublethal ischemia. Brain Res 1992; 586: 121-124.
39. Lo D, Grossberg GT. Use of memantine for the treatment of dementia. Expert Rev Neurother 2011; 11: 1359-1370.

40. Lysko PG, Gagnon RC, Yue TL, Gu JL, Feuerstein G. Neuroprotective effects of SKF 10,047 in cultured rat cerebellar neurons and in gerbil global brain ischemia. Stroke 1992; 23: 414-419.

41. Makarewicz D, Duszczyk M, Gadamski R, Danysz W, Łazarewicz JW. Neuroprotective potential of group I metabotropic glutamate receptor antagonists in two ischemic models. Neurochem Int 2006; 48: 485-490.

42. Manning SM, Boll G, Fitzgerald E, Selip DB, Volpe JJ, Jensen FE. The clinically available NMDA receptor antagonist, memantine, exhibits relative safety in the developing rat brain. Int J Dev Neurosci 2011; 29: 767-773.

43. Manning SM, Talos DM, Zhou C, Selip DB, Park HK, Park CJ, Volpe JJ, Jensen FE. NMDA receptor blockade with memantine attenuates white matter injury in a rat model of periventricular leukomalacia. J Neurosci 2008; 28: 6670-6678.

44. Muir KW, Lees KR. Clinical experience with excitatory amino acid antagonist drugs. Stroke 1995; 26: 503-513.

45. Nolan JP, Neumar RW, Adrie C, Aibiki M, Berg RA, Böttiger BW, Callaway C, Clark RS, Geocadin RG, Jauch EC, Kern KB, Laurent I, Longstreth WT, Merchant RM, Morley P, Morrison LJ, Nadkarni V, Peberdy MA, Rivers EP, Rodriguez-Nunez A, Sellke FW, Spaulding C, Sunde K, Hoek TV. Post-cardiac arrest syndrome: epidemiology, pathophysiology, treatment, and prognostication. Resuscitation 2008; 79: 350-379.

46. Obrenovitch TP. Molecular physiology of preconditioning-induced brain tolerance to ischemia. Physiol Rev 2008; 88: 211247

47. Olney JW, Wozniak DF, Jevtovic-Todorovic V, Farber NB, Bittigau P, Ikonomidou C. Drug-induced apoptotic neurodegeneration in the developing brain. Brain Pathol 2002; 12: 488-498.

48. Owley T, Salt J, Guter S, Grieve A, Walton L, Ayuyao N, Leventhal $\mathrm{BL}$, Cook EH Jr. A prospective, open-label trial of memantine in the treatment of cognitive, behavioral, and memory dysfunction in pervasive developmental disorders. J Child Adolesc Psychopharmacol 2006; 16: 517-524.

49. Parsons CG, Danysz W, Dekundy A, Pulte I. Memantine and cholinesterase inhibitors: complementary mechanisms in the treatment of Alzheimer's disease. Neurotox Res 2013; 24: 358-369.

50. Pluta R, Kocki J, Maciejewski R, Ułamek-Kozioł M, Jabłoński M, Bogucka-Kocka A, Czuczwar SJ. Ischemia signalling to Alzheimer-related genes. Folia Neuropathol 2012; 50: 322-329.

51. Pradeep H, Diya JB, Shashikumar S, Rajanikant GK. Oxidative stress - assassin behind the ischemic stroke Folia Neuropathol 2012; 50: 219-230.

52. Puisieux F, Deplanque D, Bulckaen H, Maboudou P, Gelé P, Lhermitte $M$, Lebuffe $G$, Bordet R. Brain ischemic preconditioning is abolished by antioxidant drugs but does not up-regulate superoxide dismutase and glutathion peroxidase. Brain Res 2004; 1027: 30-37.

53. Puka-Sundvall M, Hallin U, Zhu C, Wang X, Karlsson JO, Blomgren K, Hagberg H. NMDA blockade attenuates caspase-3 activation and DNA fragmentation after neonatal hypoxia-ischemia. Neuroreport 2000; 11: 2833-2836. 
54. Reynolds IJ, Miller RJ. Multiple sites for the regulation of the N-methyl-D-aspartate receptor. Mol Pharmacol 1988; 33: 581584.

55. Rice JE 3rd, Vannucci RC, Brierley JB. The influence of immaturity on hypoxic-ischemic brain damage in the rat. Ann Neurol 1981; 9: 131-141.

56. Rosamond W, Flegal K, Furie K, Go A, Greenlund K, Haase N, Hailpern SM, Ho M, Howard V, Kissela B, Kittner S, Lloyd-Jones D, McDermott M, Meigs J, Moy C, Nichol G, O’Donnell C, Roger V, Sorlie P, Steinberger J, Thom T, Wilson M, Hong Y; American Heart Association Statistics Committee and Stroke Statistics Subcommittee. Heart disease and stroke statistics-2008 update: a report from the American Heart Association Statistics Committee and Stroke Statistics Subcommittee. Circulation 2008; 117: 25-146.

57. Schwartz PH, Wasterlain CG. Determination of serum and brain concentrations of neuroprotective and non-neuroprotective doses of MK-801. J Neurol Sci 1993; 115: 26-31.

58. Scirica BM. Therapeutic hypothermia after cardiac arrest. Circulation 2013; 127: 244-250.

59. Semenov DG, Samoilov MO, Łazarewicz JW. Calcium transients in the model of rapidly induced anoxic tolerance in rat cortical slices: involvement of NMDA receptors. Neurosignals 2002; 11: 329-335.

60. Seo H, Lim KH, Choi JH, Jeong SM. Similar neuroprotective effects of ischemic and hypoxic preconditioning on hypoxia-ischemia in the neonatal rat: A proton MRS study. Int J Dev Neurosci 2013; 31: 616-623.

61. Silverstein FS, McDonald JW 3rd, Bommarito M, Johnston MV. Effects of hypoxia-ischemia and MK-801 treatment on the binding of a phencyclidine analogue in the developing rat brain. Stroke 1990; 21: 310-315.

62. Szydlowska K, Tymianski M. Calcium, ischemia and excitotoxicity. Cell Calcium 2010; 47: 122-129.

63. Thomas SJ, Grossberg GT. Memantine: a review of studies into its safety and efficacy in treating Alzheimer's disease and other dementias. Clin Interv Aging 2009; 4: 367-377.

64. Tremblay R, Chakravarthy B, Hewitt K, Tauskela J, Morley P, Atkinson T, Durkin JP. Transient NMDA receptor inactivation provides long-term protection to cultured cortical neurons from a variety of death signals. J Neurosci 2000; 20: 7183-7192.

65. Tuttolomondo A, Di Sciacca R, Di Raimondo D, Arnao V, Renda C, Pinto A, Licata G. Neuron protection as a therapeutic target in acute ischemic stroke. Curr Top Med Chem 2009; 9: 1317-1334.

66. Vanderschuren LJ, Schoffelmeer AN, Mulder AH, De Vries TJ. Dizocilpine (MK801): use or abuse? Trends Pharmacol Sci 1998; 19: 79-81.

67. Vannucci RC, Towfighi J, Vannucci SJ. Hypoxic preconditioning and hypoxic-ischemic brain damage in the immature rat: pathologic and metabolic correlates. J Neurochem 1998; 71: 1215-1220.

68. Vezzani A, Serafini R, Stasi MA, Caccia S, Conti I, Tridico RV, Samanin R. Kinetics of MK-801 and its effect on quinolinic acidinduced seizures and neurotoxicity in rats. J Pharmacol Exp Ther 1989; 249: 278-283.

69. Wachtel EV, Hendricks-Muñoz KD. Current management of the infant who presents with neonatal encephalopathy. Curr Prob Pediatr Adolesc Health Care 2011; 41: 132-153.
70. Wegener N, Nagel J, Gross R, Chambon C, Greco S, Pietraszek M, Gravius A, Danysz W. Evaluation of brain pharmacokinetics of (+)MK-801 in relation to behaviour. Neurosci Lett 2011; 503: 68-72.

71. Wrang ML, Diemer NH. MK-801 does not prevent development of ischemic tolerance in rat brain. Neuroreport 2004; 15: 11511155.

72. Xie J, Lu G, Hou Y. Role of excitatory amino acids in hypoxic preconditioning. Biol Signals Recept 1999; 8: 267-274.

73. Zhao H, Ren C, Chen X, Shen J. From rapid to delayed and remote postconditioning: the evolving concept of ischemic postconditioning in brain ischemia. Curr Drug Targets 2012; 13: 173-187.

74. Zhao $\mathrm{H}$. Ischemic postconditioning as a novel avenue to protect against brain injury after stroke. J Cereb Blood Flow Metab 2009; 29: 873-885. 